\title{
The development of the socio-cultural space of the coal-mining region as a factor of human resources retention
}

\author{
Natalia Kostiuk ${ }^{1}$, Tatiana Panina ${ }^{2 *}$, and Khash-Erdene Sambalkhundev ${ }^{3}$ \\ ${ }^{1}$ Kemerovo State Institute of Culture, Russian Federation \\ ${ }^{2}$ T. F. Gorbachev Kusbass State Technical University, Russian Federation \\ ${ }^{3}$ Mongolian Knowledge Society, Mongolia
}

\begin{abstract}
The article presents an analysis of the problem of human resource retention in the coal-mining region. It is emphasized that along with the factors of economic development it is advisable to take into account the socio-cultural needs and preferences of employees to ensure the preservation of human resources and the development of human capital on this basis. The article substantiates the need to rely on the actual sociocultural needs of the subjects of professional activity when building activities for the development of the socio-cultural space of the coalmining region. The article analyzes the implementation of strategic measures for the creation of the Siberian Cluster of Arts from the point of view of the development of the socio-cultural space of the region for the retention of human resources. The empirical part of the article is presented by the results of the study of socio-cultural needs, leisure preferences and the assessment of the attractiveness of the factors of living in Kuzbass by employees of the coal industry enterprises of the region. The sample population included 93 respondents living in the following cities: Kemerovo, Berezovskiy, Kiselevsk, Novokuznetsk, Polysaevo, and Prokopyevsk. The main method of collecting information was a survey conducted through GoogleForms. The analysis uses methods of mathematical statistics, quantitative and qualitative analysis of the results, and analysis of the significance of socio-cultural needs for the respondents.
\end{abstract}

\section{Introduction}

Human resources in the context of the issue of this scientific article are considered as the labour resources of the region. At the same time, the concept of "human resources" is used not so much from the point of view of the qualitative characteristics of employees in the coal industry, but from the point of view of the desire of employees for creative selfexpression, comprehensive development, and improvement of the general culture. That is, human resources in the presented context are considered as a set of coal mining industry

\footnotetext{
${ }^{*}$ Corresponding author: $\underline{\text { idpo@ } @ \text { kuzstu.ru }}$
} 
workers who, in addition to professional skills, skills and competencies, have the characteristics of a "social person" [1], who has their own socio-cultural needs, as well as a sense of the degree of satisfaction of these needs in the socio - cultural space of a particular region, in this case we consider Kuzbass.

On the other hand, there is no doubt that human resources, their qualitative professional and socio-cultural characteristics, are the basis for the development of human capital. That is why the problem of preserving and developing the human resources of the coal-mining region is actual and modern. The key external factors that determine the guidelines for the development of human resources as the basis for the development of human capital are the processes that dynamically occur today in Russia and its regions. The changes associated with them are determined by the goal of implementing breakthrough scientific, technological and socio-economic development of the Russian Federation, marked by the Decree of the President of the Russian Federation "On National Goals and Strategic Objectives of the Development of the Russian Federation for the period up to 2024". The issued Decree clearly defines the main areas of priority for the implementation of such a breakthrough. On the basis of the identified areas, national projects and programs have been developed at the federal level, the implementation of which should ensure the achievement of the set goals.

The goals, objectives and content of this document focus not only and not so much on the "breakthrough development" of Russia itself, but on the scientific, technological and socio-economic development of the country, which is based on the development of human capital as a set of essential forces of subjects of socio-economic activity, including not only their qualifications, but also motives, interests, ideals and values, culture, education, etc.

In the current conditions, the subjects of the Russian Federation, following the Presidential Decree, should ensure the development of priority aspects in the regions, taking into account the specifics of the regional space, as a space of special interaction of territorial, environmental, economic, social, cultural, and other factors and structures. For example, the Kemerovo Region has developed and adopted a Strategy for the socioeconomic development of the Kemerovo Region until 2035, the strategic goal of which is "to ensure the rapid development and competitiveness of the economy and social sphere, as well as to achieve a leading position in terms of the quality of life of the population and the level of human capital development" [2].

At the same time, in a number of industrial regions, the trend of outflow of human resources continues. The Kemerovo region is no exception. Kuzbass, while maintaining its position as a region whose core economy is coal mining, is gradually moving away from such a one-sided orientation and is turning into a region with powerful and diverse industrial complexes in various fields. This must also lead to the rise of the cultural level of the population, the diversification and deepening of socio-cultural needs and preferences, the "modernization" of the region, its accelerated modernization in many aspects. Nevertheless, in recent years, one of the disturbing factors that compel special attention is the outflow of the population from Kuzbass, especially young people. The most promising personnel are leaving, as elements of the region's human capital, which casts doubt on its cultural potential and becomes a threat to the future of the region [3].

So, according to media reports (2019) Kemerovo State Statistics Service reported on the demographic situation in the region. Even a cursory analysis of the data shows that since 2002, there have been 300,000 fewer residents aged 15 to 29 in the region. This aspect is of particular concern to scientists in the region, and a number of fundamental studies and publications are devoted to it $[4,5,6,7,8]$. Against this background, not only the actual environmental problems of the region are becoming more acute, but also, most importantly, their perception by residents, which leaves an imprint on the perception of other areas of the region's life, including socio - cultural one. According to a number of public surveys, 
ecology is an important, but not the only, and often not the main factor in leaving the region. Often, the main factor in the outflow of young people who go to study in other regions after school and do not return to Kuzbass is the lack of vision of prospects both in professional activities and in the implementation of socio-cultural needs.

\section{Materials and methods}

In the context of preserving the human resources of the coal-mining region, which is Kuzbass, on the basis of taking into account the socio-cultural needs of the population, an analysis of the results of a sociological survey has been conducted within the framework of a scientific project supported by the Russian Foundation for Basic Research (RFBR) and the Kemerovo region-Kuzbass. Project topic: Socio-cultural needs of the population of Kuzbass in the context of the development of the cluster of arts: socio-philosophical and psychological-pedagogical aspects of identifying and forming attractors.

\section{Results and discussion}

For the analysis within the framework of the topic of this article, the responses of respondents who made up a group of employees of coal mining enterprises were selected. Within the main array of survey participants (more than 10,000 respondents-residents of Kemerovo and the Kemerovo region of different socio-professional status and affiliation), the corresponding group of respondents was 93 people. Taking into account the requirements for the representativeness of the sample population when conducting sociological research and the general purpose of the main study, which analyzes the results of the survey of this group of respondents, it is advisable to consider the following results as the results of a pilot study. The pilot study allows us to identify the presence of certain trends in the general population of interest (employees of coal mining enterprises) and to outline ways for further scientific research of the problem.

Thus, the positions of the questionnaire concerning what socio-cultural needs are important for the representatives of the given professional group, as far as these same needs, from the point of view of the respondents' satisfaction were analyzed. Questions about the preferred forms of leisure activities were also asked. In addition, to form a general picture of the respondents' attitude to the situation of living in the Kemerovo region, the responses of this group of respondents were analyzed to assess the factors of attractiveness of living in Kuzbass. The survey was conducted using Google Forms.

The analysis uses methods of mathematical statistics, quantitative and qualitative analysis of the results, and analysis of the significance of socio-cultural needs for respondents.

Thus, the sample population consisted of 93 employees of the enterprises of the coal mining industry of Kuzbass. Among them, $64.5 \%$ (60 rep.) live in the city of Kemerovo, $35.5 \%$ (33 rep.) live in the cities of Berezovskiy, Kiselevsk, Novokuznetsk, Polysaevo, Prokopyevsk. The gender distribution of the respondents was approximately equal: $51.6 \%$ of the survey participants were women, $48.38 \%$ were men.

First of all, the respondents' assessment of the attractiveness of the factors of living in Kuzbass was analyzed. Respondents were asked to evaluate on a four - point scale (where "4" - very attractive; " 3 " - rather attractive; "2" - rather not attractive; "1" - not at all attractive) the degree of attractiveness of the following factors for them personally: the situation with work and employment; the state of high-tech industries, the economy; features of cultural communication; features of urban space; the opportunity for selfexpression; the opportunity to diversify leisure; the level of wages; availability and quality 
of cultural events; ecology. The following results were obtained during statistical processing: the average score for the proposed factors did not exceed 2.32 out of a possible 4 (Table 1). Nevertheless, this assessment characterizes the tendency to evaluate certain factors more positively, as tending to the indicator "rather attractive" than to the indicator "rather not attractive". The factors of living in Kuzbass were estimated at 2.32 points, such as: the situation with work and employment; the state of high-tech industries, the economy; features of cultural communication. The lowest average score was scored by the factor "ecology" (1.68 points out of 4$)$, which indicates a negative attitude of respondents to the state of the environment in the region, which generally corresponds to official statistics and published data from other studies conducted in the region.

Table 1. Assessment of the degree of attractiveness and unattractiveness of factors of residence in Kuzbass

\begin{tabular}{|c|l|c|}
\hline № & \multicolumn{1}{|c|}{ Factors } & $\begin{array}{c}\text { Average score } \\
\text { (max. 4) }\end{array}$ \\
\hline 1 & The situation with work and employment & 2,32 \\
\hline 2 & Condition of high-tech industries, economy & 2,32 \\
\hline 3 & Features of cultural communication & 2,32 \\
\hline 4 & Features of urban space & 2,26 \\
\hline 5 & Opportunity for self-expression & 2,26 \\
\hline 6 & The opportunity to diversify your leisure time & 2,23 \\
\hline 7 & Salary level & 2,10 \\
\hline 8 & Availability and quality of cultural events & 2,10 \\
\hline 9 & Ecology & 1,68 \\
\hline
\end{tabular}

The average indicators for the factors "features of urban space" and "opportunity for self-expression" ( $2.26 ; 2.26$ points out of 4 , appropriately) tend to assess these factors as "more attractive than not attractive". The average indicators for the factors "opportunity to diversify leisure", "salary level" and "availability and quality of cultural events" tend to be rated "rather not attractive than attractive" $(2.23 ; 2.1 ; 2.1$ points out of 4 , appropriately).

As follows from the analysis of the factors of attractiveness of living in Kuzbass, in accordance with the problem covered in the article, the opportunity to diversify leisure activities is rather negatively evaluated. The results of the respondents' responses to the question about their preferred forms of spending their own leisure time are presented below. When answering this question, it was suggested to choose no more than three options from the suggested ones. Among them: walking down the street and / or going out into nature; hobbies, personal computer, laptop, tablet; reading books, periodicals; visiting cultural institutions (theaters, museums, philharmonic halls, etc.); watching TV; playing sports. The results of the respondents' choice of preferred forms of leisure activities are shown in Figure 1. 


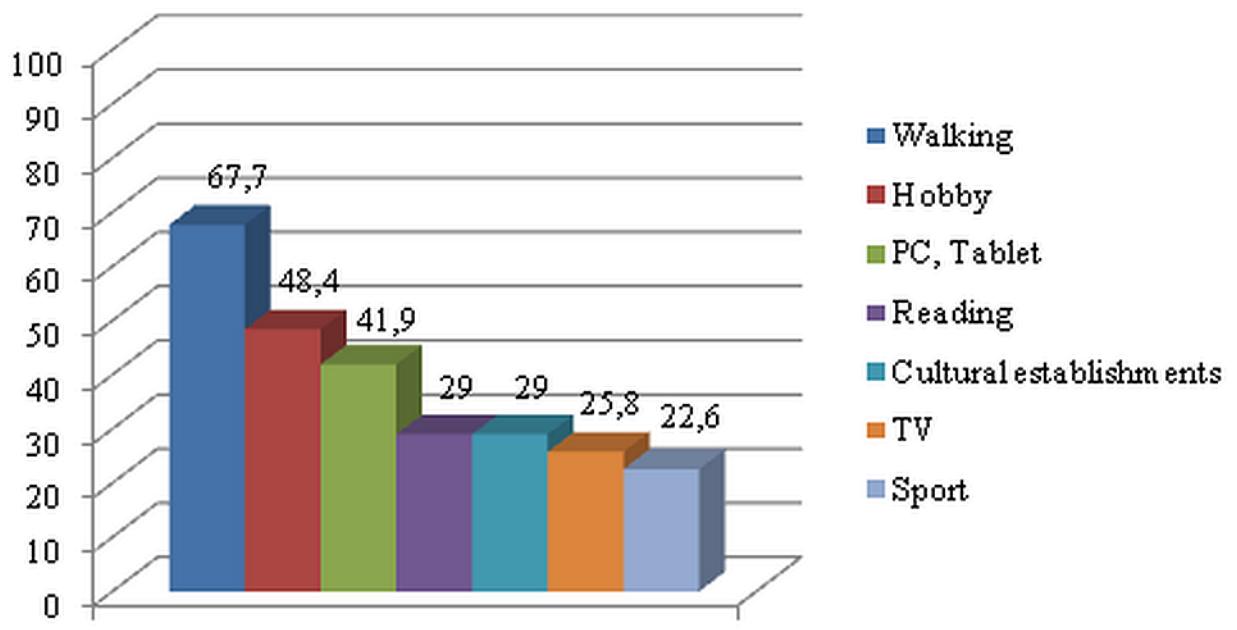

Fig. 1. Preferred forms of leisure activities (number of choices, \%)

More choices $(67.7 \%)$ were made by respondents regarding the position of "walking down the street, going to nature". Correlating the respondents' preference for such leisure activities with an insufficiently high assessment of the attractiveness of the features of urban space ( 2.26 points out of 4 ), we can conclude that the development of the urban environment is actual from the point of view of the forms of leisure activities that are relevant for residents.

Almost $50 \%$ of the choices are made in favor of hobbies that are not related to professional activities. The third position is occupied by leisure activities in a virtual environment (41.9\% of the choices). A comment is required here: when formulating this position, it was clarified that it is leisure activity that is not related, for example, to selfeducation. At the same time, the possibility of reading e-books and magazines, news, viewing performances, concerts, movies, etc. by the respondents was not excluded, since within the framework of this study, there was no task of such differentiation.

With a sufficient "gap" from the leading forms of leisure (by more than 10\%), "reading books and periodicals", "visiting cultural institutions", "watching TV", "playing sports" was chosen $(29,0 \% ; 29,0 \% ; 25,8 \% ; 22,6 \%$ choices particularly). In the context of the data presented above, it can be hypothesized that fewer choices for positions 4 and 5 are associated with the replacement of real objects (books) and visits to real theaters, museums, etc. with a virtual environment. But this hypothesis requires further development.

Let us turn to the analysis of the significance of the actual socio-cultural needs of employees of coal mining enterprises and the assessment of the degree of satisfaction of these needs by respondents. In the conducted research, socio-cultural needs are interpreted as a synthesis of the social and cultural needs of the subject, which are formed and transformed in the process of socialization in a particular cultural environment, in a particular society. Socio-cultural needs determine the direction of the subject's life activity and cause the appearance of such social phenomena as progress-regression, creativityconformity, etc. The analysis of primary sources and previous studies allowed us to determine the list of socio-cultural needs offered to the respondents. It includes sociocultural needs:

in an interesting job;

in getting an education;

in communication; 


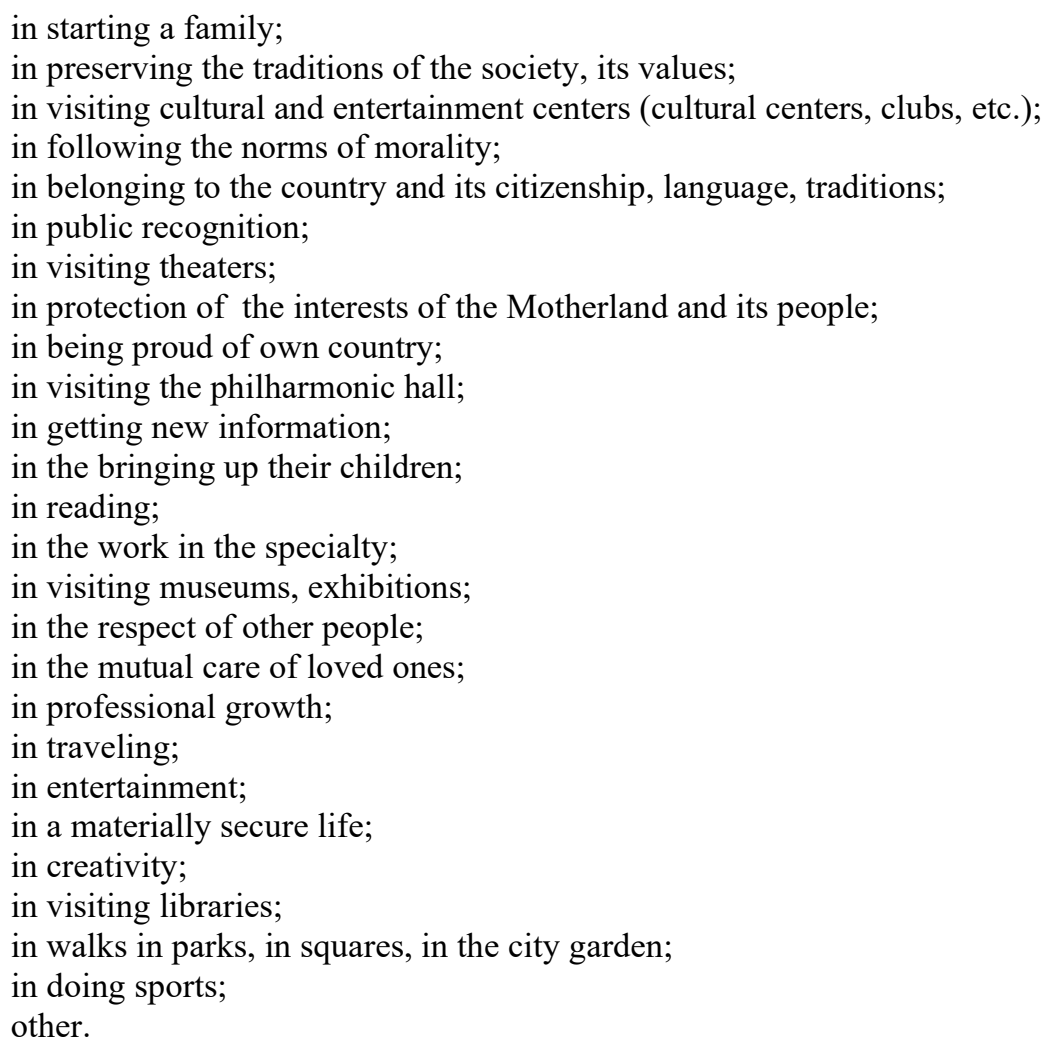

In the course of the study, respondents were asked to assess the degree of significance for them personally of each of the presented socio-cultural needs on a five-point scale (where " 5 " means very important; " 4 " means more important than not; " 3 " means difficult to answer; " 2 " means rather not important than important; "1" means not important at all). The analysis of the results allowed us to build a rating of socio-cultural values that demonstrate the presence of the following trends.

First, the average arithmetic values obtained as a result of statistical processing of the results do not fall below 3 points that is an indicator of the situation when the respondent doubts the assessment of the importance - unimportance of the need and, moreover, a confident assessment of the low significance of the socio-cultural need. This can be interpreted as a positive trend in the respondents' assessment of the importance of all the presented socio-cultural needs.

Secondly, drawing parallels between the existing classifications of needs in science, it should be argued that the first three positions of the rating are occupied by needs that can be classified as "basic". This is the need for mutual care of loved ones (average value $=4.52$ ), the need to create a family (average value $=4.45$ ), the need for a financially secure life (average value $=4.42$ ). Also, the third position is occupied by the need for professional growth (average value $=4.42$ ). This is followed by educational needs (position 4). The fifth position in importance, with an equal average value (4.26), is occupied by the needs for interesting work, for bringing up their children, and for traveling.

Third, referring to the importance of socio-cultural needs directly related to the topic of the article, it can be argued that there is a negative trend in assessing the importance of cultural infrastructure facilities in the region, such as a museum, theater, library, philharmonic hall, which, at the same time, are designed to create an interesting, developing, comfortable socio-cultural space. Thus, the socio-cultural needs associated 
with visiting museums and exhibitions, visiting theaters, visiting libraries, and visiting the philharmonic hall occupy the last places in the rating: from 16 to 19 , particularly. We emphasize that the highlighted trend is not declared in terms of the quality of the activities of these cultural institutions, it demonstrates the low relevance of these needs for respondents. At the same time, as indicated above, in general, the rating of these needs is positive. The full list of socio-cultural needs with the distribution of average values is presented in Table 2 .

Table 2. Distribution of average values for assessing the importance of socio-cultural needs of employees of coal mining enterprises

\begin{tabular}{|c|c|c|}
\hline Socio-cultural need & Rank & Average Value \\
\hline In the mutual care of loved ones & 1 & 4,52 \\
\hline In creating a family & 2 & 4,45 \\
\hline In a financially secure life & 3 & 4,42 \\
\hline In professional growth & 3 & 4,42 \\
\hline In getting an education & 4 & 4,29 \\
\hline In an interesting job & 5 & 4,26 \\
\hline In the bringing up their children & 5 & 4,26 \\
\hline In travelling & 5 & 4,26 \\
\hline In following the norms of morality & 6 & 4,23 \\
\hline In entertainment & 7 & 4,16 \\
\hline In communication & 8 & 4,10 \\
\hline In getting new information & 8 & 4,10 \\
\hline In the work in the specialty & 8 & 4,10 \\
\hline In walks in parks, in squares, in the city garden & 8 & 4,10 \\
\hline In the respect of other people & 9 & 4,06 \\
\hline In doing sports activities & 10 & 4,00 \\
\hline In belonging to the country and its citizenship, language, traditions & 11 & 3,94 \\
\hline In preserving the traditions of society, its values & 12 & 3,87 \\
\hline In doing creative work & 12 & 3,87 \\
\hline In protecting the interests of the Motherland and its people & 13 & 3,84 \\
\hline In being proud of own country & 14 & 3,74 \\
\hline $\begin{array}{l}\text { In visiting cultural and entertainment centers (cultural centers, } \\
\text { clubs, etc.) }\end{array}$ & 14 & 3,74 \\
\hline
\end{tabular}




\begin{tabular}{|l|c|c|}
\hline In reading & 14 & 3,74 \\
\hline In public recognition & 15 & 3,58 \\
\hline In visiting museums and exhibitions & 16 & 3,42 \\
\hline In visiting theaters & 17 & 3,39 \\
\hline In visiting libraries & 18 & 3,26 \\
\hline In visiting the Philharmonic hall & 19 & 3,13 \\
\hline
\end{tabular}

It is interesting that the socio-cultural need for entertainment in the rating of respondents occupies the seventh position, while the needs for visiting theaters, museums, philharmonic halls, etc. are only the last places. It seems appropriate to further study the semantic space of the category "entertainment" of Kuzbass residents, since the revealed fact concerns not only representatives of this sample population, but also samples of other categories of respondents participating in the main study. Such work can become the basis for the development of measures to harmonize the current situation: through an appeal to the semantic content of the category "entertainmen", based on the current needs and meanings of the residents of the region, to the development of socio-cultural needs in visiting cultural and art institutions, in participating in socio-cultural events.

Drawing a line under the analysis of the results of the survey of employees of coal mining enterprises, we present data concerning the attitude of respondents to living in Kuzbass - leaving the region, the issue directly related to the problem of this scientific article - the preservation of human resources. In the current study, adult respondents were asked an indirect question, which, however, allows them to identify such an attitude. The question is formulated as follows: would you like your children and grandchildren to stay in Kuzbass? The results are as follows (Fig. 2): almost half of the respondents (48.38\%) give a negative answer ("no"). Only $12.9 \%$ respond positively to the question. The reasons (factors) by which the respondents explained their position are analyzed above are presented in Table 1.

Would you like your children and grandchildren to stay in Kuzbass?

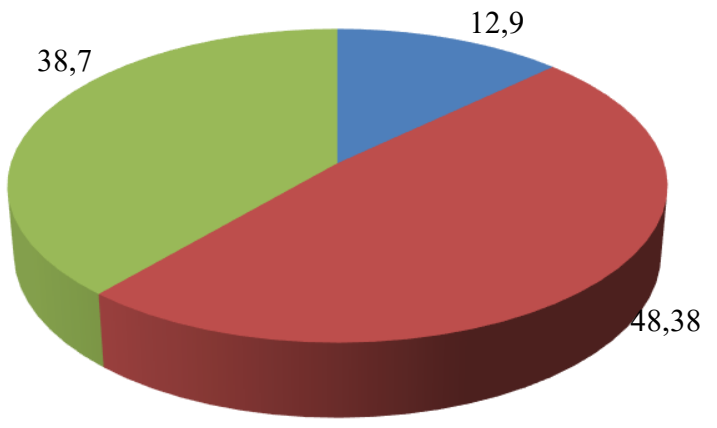

- Yes

- No

$\square$ I find it difficult to answer

Fig. 2. Distribution of employees' responses of coal mining enterprises to the question 
about the potential residence of children and grandchildren in Kuzbass

At the same time, we emphasize that $38.7 \%$ of respondents found it difficult to answer the question categorically. This should be considered as a positive trend, as respondents indicate that if the socio-economic situation in the region changes, including the development of socio-cultural space, the urban environment and the expansion of opportunities for creative self-realization of young people, their opinion would change in a positive direction.

Thus, speaking about the major transformations of the economy of Kuzbass, it is impossible to underestimate the strategic tasks of transformations in the socio-cultural sphere, designed to change the image of the region, primarily in the perception of its residents, to create conditions for the realization of creative needs, meeting their sociocultural needs of different levels. Moreover, the implementation of the strategic objectives of the region's development is based on purely socio-cultural factors [9].

One of the mechanisms by which changes in the socio-cultural space of the Kuzbass are initiated is the creation of the largest cultural cluster - the Siberian Cluster of Arts. Today, measures are being actively implemented to form the cluster infrastructure already, select highly qualified personnel to implement the work of the cluster institutions, and develop programs for the activities of institutions, the implementation of which creates conditions for the optimal development of the modern, innovative socio-cultural environment of the Kemerovo region as a basis for preserving human resources and developing the region's human capital.

The structure of the arts cluster includes three major infrastructure blocks:

Siberian Branch of the State Academic Mariinskiy Theatre;

Museum and exhibition complex;

Cultural and educational complex.

In addition to the infrastructure differentiation of the cluster elements, the focus of each of them on specific goals in the development of the socio-cultural space of Kuzbass and the focus on the implementation of special content functions is obvious.

For example, the Siberian branch of the State Academic Mariinskiy Theater is designed to provide an opportunity for residents of the coal-mining region to get in touch with worldclass works of opera and ballet in "real" time, attending performances and concerts. Providing the branch with modern equipment creates conditions for inviting leading Russian and world theater groups and opera and ballet soloists to Kuzbass. In addition, the formation and development of its own troupe and symphony orchestra involves the tour of the artists of the Siberian branch of the State Academic Mariinskiy Theater outside of Kuzbass in the cities of the Siberian Federal District and Russia as a whole.

The museum and exhibition complex is designed to combine in joint activities a branch of the State Russian Museum and the Kuzbass Art Center, as well as a new storage facility and a restoration center. The museum and exhibition complex, as an element of the art cluster, will allow us to accumulate many years of experience in the work of museums in the region and develop museum and exhibition activities in accordance with the world's leading trends in the museum business. The museum and exhibition complex will complement the multifunctional cinema and concert complex.

In terms of content, the functioning of this element of the Siberian Cluster of Arts involves the work of exhibition halls, which will present works of fine art by Siberian, Russian and world authors. In addition, it is planned to implement the cultural and educational component: the organization of creative studios of various directions for children, youth and adults.

Finally, the Cultural and Educational Complex of the Siberian Cluster of Arts is designed, first, to provide training of highly qualified personnel, primarily for the objects of 
the cluster itself. Secondly, the development and full functioning of the cultural and educational complex will allow for the training of personnel for the institutions of the arts and culture of neighboring regions and the country as a whole.

The cultural and Educational complex of the Siberian Cluster of Arts includes:

a branch of the Moscow State Academy of Choreography;

a branch of the Central Music School at the Moscow State Tchaikovsky Conservatory;

the School of Creative Industries;

the Siberian Campus of the Russian State Institute of Performing Arts.

We pay attention that the first three elements of the Cultural and Educational Complex are aimed at educational activities with the younger generation of Kuzbass residents. Moreover, the experience of organizing training in the branches of the Moscow Academy of Choreography and the Central Children's Music School will be new for the region. The implementation of pre-professional education programs in these institutions allows children who feel a vocation for music and ballet classes and have a talent for such activities to purposefully master the profession of a musician-performer or ballet soloist from an early age.

The School of Creative Industries is aimed at creating conditions for children and teenagers to gain practical skills in the space of multimedia technologies, sound design, working in modern graphic editors, etc. In addition, students have already taken the first steps and received specific "products" of their creative activity in the designated areas, as well as in the application of modern experimental theater technologies.

\section{Conclusion}

Thus, the strategic goal of creating a Siberian cluster of arts on the territory of the Kemerovo region-Kuzbass, which, while maintaining its appearance of a coal-mining region, strives to create a developed socio-cultural space, comfortable for living, with a modern infrastructure of culture and leisure, is obvious. It is the creation of such conditions that can ensure the safety of human resources in the region, primarily through the development of the interests of the adult population to the ongoing cultural events, involvement in them on the basis of relevant socio-cultural needs and preferences for residents. But an equally important factor is the inclusion of the younger generation in the activities of the elements of the cluster of arts: educational, cultural-educational, sociocultural. It is this trend that will allow us to maintain and develop an interest in living in the territory of our native region, especially when choosing a future professional activity related to coal mining, thereby ensuring the preservation of human resources in the region.

Acknowledgments: The reported study was funded by RFBR and Kemerovo region-Kuzbass, project number № 20-413-420004.

\section{References}

1. S. N. Mikhailov, V. V. Pchelkina, Bulletin of the Chuvash University, 1, 299 (2013)

2. N. V. Kostyuk, T. S. Panina, E. A. Pakhomova, The world of science, culture, and educatio, 3, 82, 44 (2020)

3. N. V. Kostyuk, V. I. Markov, T. A. Volkova, A. S. Telmanov, Z. M. Akhmetgaleeva, A. O. Golskaya, The formation of the quality of the cultural environment in small urban and rural areas : proceedings of the Russian scientific and practical conference, $31(2020)$ 
4. E. I. Levina, Dynamics and inertia of reproduction of the population and the replacement of generations in Russia and the CIS, 2, 370 (2016)

5. E. A. Morozova, A. N. Chelombitko, L. M. Andreeva, Bulletin of Kemerovo State University, 2, 213 (2012)

6. T. N. Protasova, XIX Ural sociological readings: Regional features of development and implementation of social policy: proceedings of all-Russia. nauch.-pract. Conf., 271 (2013)

7. T. N. Protasova, Bulletin of the Kemerovo State University. Series: political, sociological and economic Sciences, 4, 14, 367 (2019)

8. V. A. Kryukov, Yu. A. Fridman, G. N. Rechko, E. Y. Loginov, Kuzbass in the new time (Publishing house of the Institute IEOPP SB RAS, Novosibirsk, 2020)

9. I.V. Novikov, at all, Strategizing of human potential of Kuzbass (KemSU, Kemerovo, 2020) 